\title{
An Autopsy Study of Brought Dead Cases at a Tertiary Care Hospital in Port Blair, Andaman and Nicobar Islands
}

\author{
Udayashankar Yadiyapur ${ }^{1}$, A.K. Malle ${ }^{2}$, Deepak H.D' Souza ${ }^{3}$ \\ ${ }^{1}$ Associate Professor, ${ }^{2}$ Assistant Professor, ${ }^{3}$ Professor \& HOD, Dept. of Forensic Medicine \& Toxicology, \\ Andaman Nicobar Islands Institute of Medical Sciences (ANIIMS), Port Blair, A \& N Islands.
}

\begin{abstract}
Introduction: Brought dead cases are considered as Medico-legal Cases which require investigation by law enforcing authorities, to know the cause of death and then decide whether it is a Natural/Unnatural death. The doctor's post mortem report gives direction to the police in their investigation.

Method: All cases during the study period i.e. from $1^{\text {st }}$ Jan 2019 up to $31^{\text {st }}$ Dec 2019 were that were brought dead to GB Pant Hospital (GBPH), which is a tertiary care hospital attached to ANIIMS were included. All these cases were retrospectively analysed under various parameters.
\end{abstract}

Results: The present study reveals that out of 223 cases, 58 were brought dead to GBPH. Out of these in 57 cases the death was due to a Natural cause and in only one case it was due to an unnatural cause.

Keywords: MLC case, Medico-legal Case, Natural deaths, Unnatural deaths, Criminal Justice System, Brought Dead cases.

\section{Introduction}

After the birth of a person, death is sure and certain. This is the universal law of existence. Because of the complexities of life, factors like socio economic conditions, thoughts, habits, behaviours, physical and mental health- affect the life span of a person. Any death which is suspicious, and where there is some foul play, disturbs the peace of the family, community and ultimately the society.

Natural death means death occurring due to some natural disease or pathological condition, old age, or devitalisation; here the death is not intended or attempted and also does not occur accidentally ${ }^{(1)}$. Deaths

\section{Corresponding Author:}

\section{Dr. AK Malle}

Assistant Professor Dept. of Forensic Medicine \& Toxicology, ANIIMS, Port Blair, Andaman \& Nicobar Islands

e-mail: mak101282@hotmail.com other than due to natural causes- Suicides, homicides, accidental deaths- are termed as 'Unnatural Death'. This division of death into- 'natural' and 'unnatural death' is very crucial for the police. Naturally, the police will need to investigate all the unnatural deaths to bring the case to a logical conclusion and thereby apprehend and punish the criminals and protect the innocents; thus maintaining law and order in the society and bring peace and prosperity.

Criminal Justice System comprises of the police, the judiciary and corrective system [prison department]. Although society maintains other forms of social control such as family, school, religious institutions, they are designed to deal with moral, and not legal mis- behaviour. Only Criminal Justice System has the power to control crime and punish criminals. And the doctor being in a responsible position in the society, shall support the system while discharging his duties.

The brought dead case or dead on arrival is such a situation that the attending doctor cannot certify whether it is natural death or unnatural death. If he satisfies himself, that it is due to some natural cause he will 
issue the death certificate and if he suspects some foul play, he will make it a medicolegal case and informs the police. Thereafter, the police will hold the inquest and if the investigation officer of the case, finds any suspicion in the causation of the death, he will send the body for medicolegal autopsy, during which the cause of death, time since death, manner of death - natural or unnatural are opined.

Therefore, the cases which are brought dead are routinely registered as medicolegal cases and police are informed and death certificate is not issued and the body is not released to the relatives ${ }^{(2)}$.

The present study is aimed to analyse the brought dead cases in terms of natural and unnatural; sex \& age incidences; and the cause of death.

\section{Materials and Method}

In the present study we retrospectively assessed all cases that were brought dead to GB Pant Hospital. Relevant data was extracted from the Post-mortem reports. Out of the total 223 cases subjected to post mortem examination 58 were brought dead to GBPH
Casualty department and tabulated into MS Office Excel Sheets and later tabulated using SPSS Version 21.

\section{A. Criteria for case selection}

1. Both male and female victims were taken into consideration

2. All age groups are included in the study

3. All types whether natural or un natural are included in the study

\section{B. Collection of data}

1. Inquest report of police- address, age, sex, religion, place, time and date of occurrence of death.

2. Previous history of the case- from the relatives/ friends/co-workers of the deceased.

3. Medical documents - old case sheets, medication history $\&$ date and time of declaration of death.

4. During autopsy- whether the findings corroborates with apparent cause of death or not. External and internal findings are considered.

\section{Results}

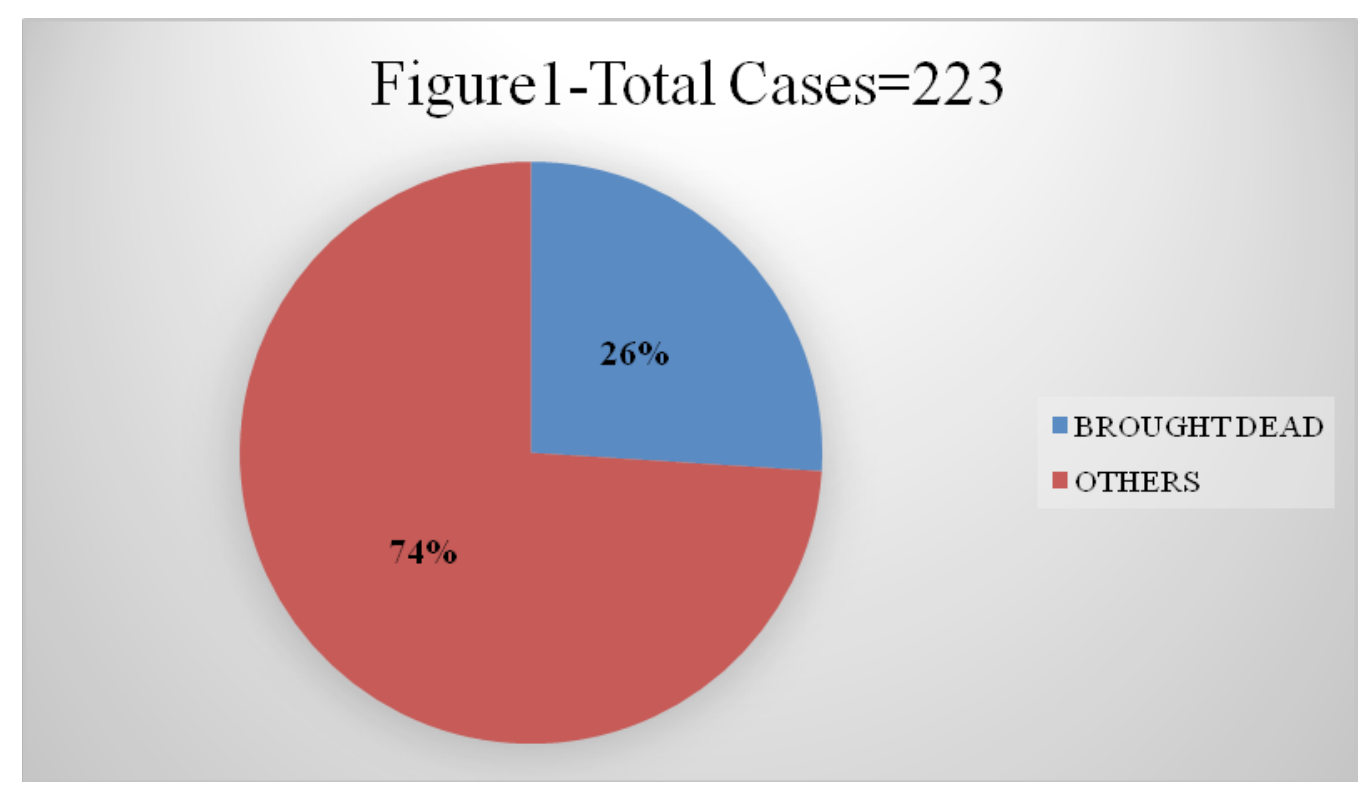




\section{Figure 2- Age wise distribution}

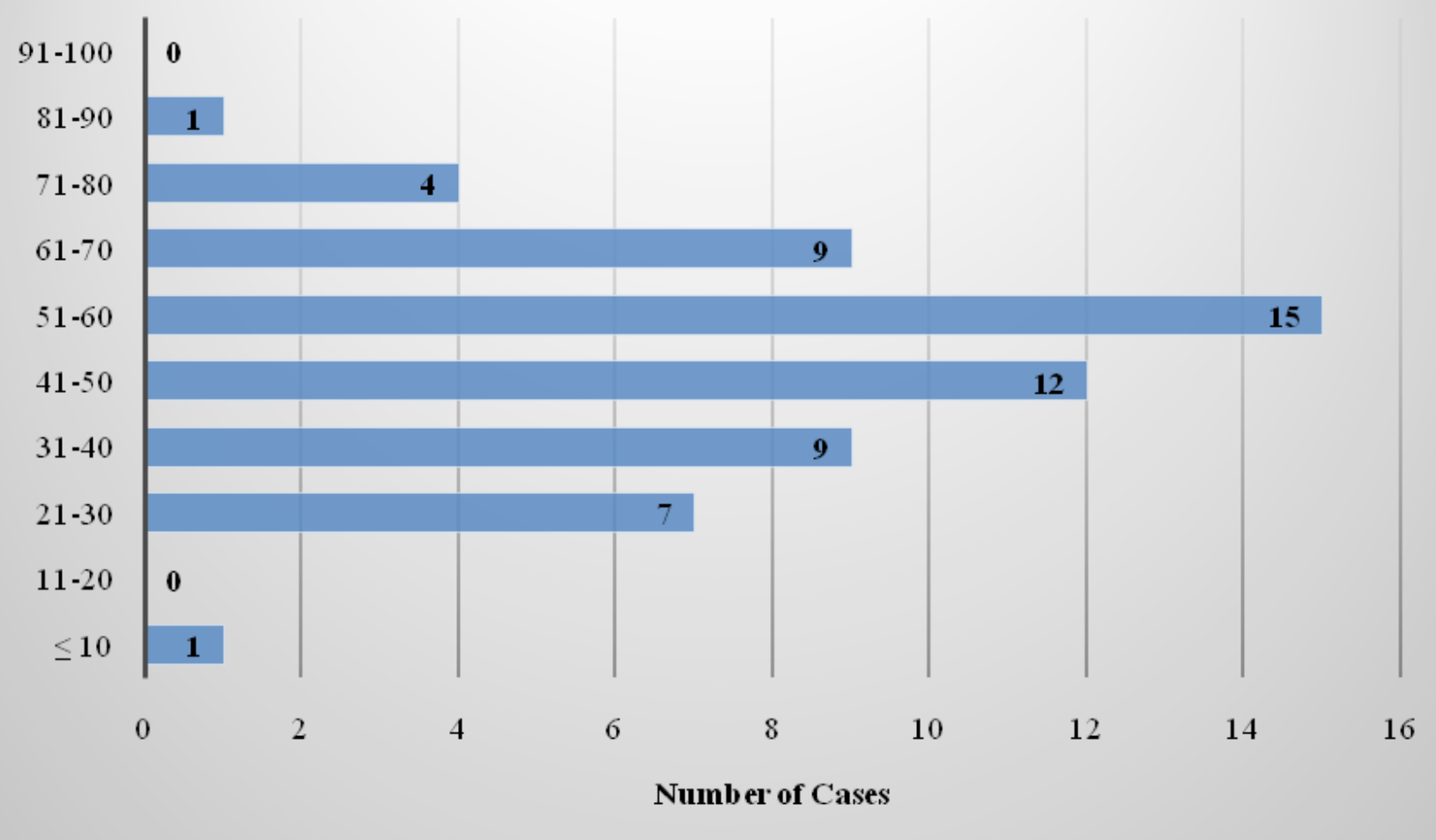

Figure 3- Sexwise Distribution of Cases

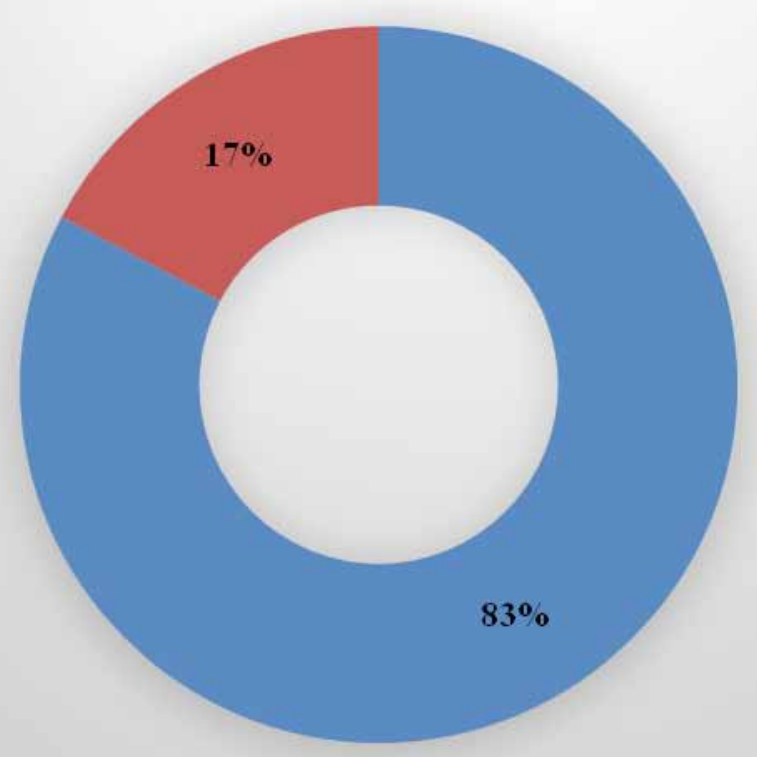

- Male

-Female 


\section{Figure 4- Ratio of Natural and Unnatural Cases}
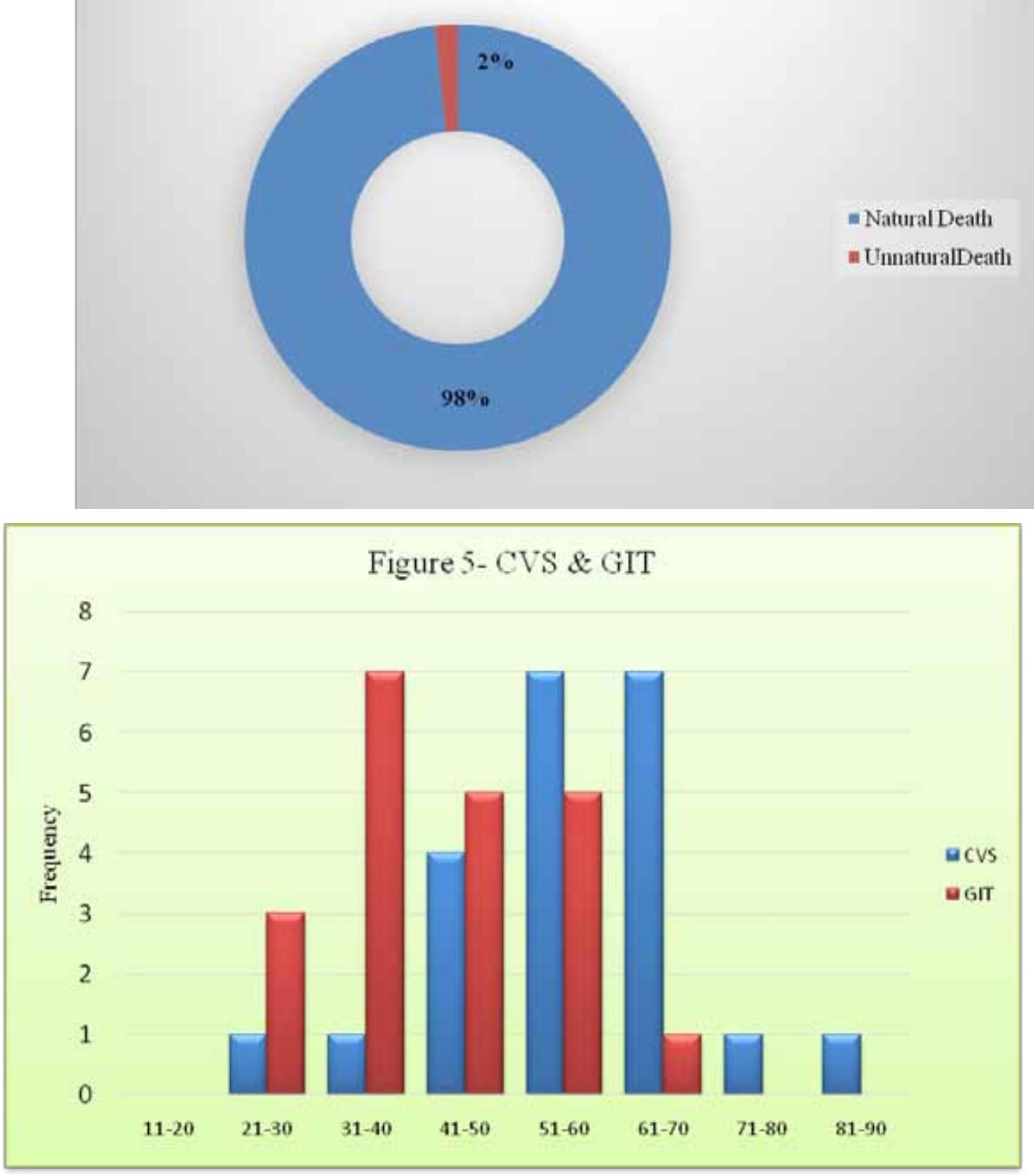

Table 1: Different causes of death- for natural deaths

\begin{tabular}{|l|c|c|}
\hline System & Total no of cases & $\mathbf{\%}$ \\
\hline Cardio-vascular System (CVS) & 22 & 37.58 \\
\hline \multirow{2}{*}{ Gastro-intestinal System (GIT) \& FSL reserved (GIT) } & 16 & 27.58 \\
\cline { 2 - 3 } & 05 & 08.62 \\
\hline Respiratory System (RS) & 09 & 15.51 \\
\hline Central Nervous System (CNS) & 05 & 08.62 \\
\hline Infectious Disease & 01 & 01.72 \\
\hline Total & $\mathbf{5 8}$ & $\mathbf{1 0 0}$ \\
\hline
\end{tabular}




\section{Discussion and Analysis}

In the present study (Figure 1) out of all 223 post mortem examination cases conducted at GBPH, 58 cases were brought dead to the Casualty Department of GBPH which is $26 \%$. This closely correlates with the study conducted by N. L. Disania et $\mathrm{al}^{9}$, who reported that $31.70 \%$ cases were brought dead and much higher than reported by B. D. Gupta etal ${ }^{10}$ who reported that $10.7 \%$ cases were brought dead. It is much lower than the study conducted by Apurba Biswas et al ${ }^{11}$ who reported $58.33 \%$ of all cases were reported brought dead. Age wise distribution (Figure 2) of the brought dead cases and reveals that, the number of brought dead cases in the extremes of age are less and age group of 51-60 has maximum number of deaths i.e. $25.86 \%(n=15)$, this differs from N. L. Disania et $\mathrm{al}^{9}$ who reported that age group of $3^{\text {rd }}$ decade had maximum deaths $27.27 \%$, while Gupta et $\mathrm{al}^{10}$ reported that $31-50$ age group topped at $48.89 \%$.

Sex wise distribution (Figure 3) of the brought dead cases, reveals a male to female sex ratio of $4.88: 1$, while N. L. Disania et $\mathrm{al}^{9}$ reported 1:0.18; Gupta et $\mathrm{a}^{10}{ }^{10}$ reported it at 5.92:1 and Apurba Biswas et $\mathrm{al}^{11}$ reported it at $4.40: 1$.

In this study (Figure 4) Natural Deaths were 98.27\% $(\mathrm{n}=57)$ vs Unnatural Deaths is $1.72 \%(\mathrm{n}=1)$. This differs from Disania et al, who reported Natural Deaths at $21.9 \%$ and Unnatural Deaths at $78.1 \%$ and Apurba Biswas et $\mathrm{al}^{11}$ who reported Natural Deaths at $9.76 \%$ and Unnatural Deaths at $88.92 \%$.

Figure 5 depicts distribution of deaths due to CVS and GIT disease. In this study deaths due to cardiovascular deaths in females were prevalent only in the age group of 61-70 years (females 6; males only $1 \mathrm{n}=7$ ). Similarly deaths due to cardiovascular diseases in males was prevalent mostly in the age group 51-60 $(n=7)$. Deaths due to GIT diseases were prevalent in males only.

Table 1depicts different causes of natural deaths; the CVS contributes more numbers $(n=22)$, followed by GIT $(n=21)$ in which all deaths are due to chronic liver disease. Out of these in 5 cases, viscera has been sent for chemical analysis for the confirmation of alcoholthese showed features of chronic liver disease also and therefore included in GIT category. All these cases had a history of chronic alcoholism. RS, CNS and Infectious disease (in this case it was Falciparum malaria which was proved by lab investigation).
Research shows that almost every system in the body can be influenced by chronic stress. When chronic stress goes unreleased, it supresses the body's immune system and ultimately manifests as illness. Fight or flight is the response to the stress. During this time heart rate, blood pressure, breathing, muscle tension, digestion, metabolism will all increase. Normally it should return to normal within 3 minutes. But because of faulty conditioning, this will continue leading on to chronic stress. To combat stress, person will resort to alcohol or tobacco which both are in high prevalence in Andaman. 3,4

Coronary Heart disease has long been regarded as a classical psychosomatic illness. There is a strong evidence that psychological stress is a significant risk factor for coronary heart disease and mortality $5,6,7,8$ Tennant found that a positive relationship between life stress and cardiac infarction and sudden death; while study by Rosengren et al. ${ }^{7}$ reported that mortality was increased two folds for men for experiencing 3 or more antecedent life stressful events. The INTERHEART study ${ }^{8}$ revealed that people with myocardial infarction reported higher prevalence of 4 stress factors: stress at work and at home, financial stress and major life events in the past year.

\section{Conclusion}

The present study reveals that almost all the brought dead cases are Natural Deaths. Diseases of the cardiovascular system and gastrointestinal system are major contributors. With respect to GIT, all deaths are due to Alcoholic Liver Disease and all are males. Both tobacco and alcohol addiction being high in Andaman's Port Blair are major contributors to these natural deaths.

Acknowledgements: We sincerely thank the Investigating Officers, relatives and Mortuary Staff of G B Pant hospital attached to ANIIMS, Port Blair.

\section{Conflict of Interest: Nil}

\section{Source of sponsorship or funds received: Nil}

Ethical Clearance: Not required, as the study is retrospective and non-invasive.

\section{References}

1. Krishan Vij 'Text book of Forensic Medicine and Toxicology' $5^{\text {th }}$ Ed. 2011; p 100.

2. Dr. K S Narayan Reddy and Dr. O P Murthy, 'The 
Essentials of Forensic Medicine and Toxicology' $34^{\text {th }}$ Ed.2017; p 22.

3. Manimunda S P et al. BMC Public Health. 2012. Tobacco use and Nicotine dependency in a cross-sectional representative sample of 18,018 individuals in Andaman and Nicobar Islands, India.

4. Manimunda S P et al. Indian Journal of Public Health. 2017. Apr-Jun. Alcohol consumption, hazardous drinking and alcohol dependency among the population of Andaman and Nicobar Islands, India.

5. Chockalingam A, Venkatesan S, Dorairajan S et al 'Estimation of subjective stress in acute myocardial infarction' J postgrad Med. 2003,49:207-10. [PubMed] [Google Scholar]

6. Tennant C. Life stress, social support and coronary heart disease, Aust NZ Journal of Psychiatry. 1999; 33:636-41[PubMed] [Google Scholar].

7. Rosengren A, Orth Gomer K, Wedel H, et al Stressful life events, social support and mortality in men born in 1933. Brit Medi J. 1993; 307: 1102-5. [PMC free article] [PubMed] [Google Scholar]

8. Rosengren A, Hawken S, Ounpu S et al. Association of psychological risk factors with risk of myocardial infarction in 11,119 cases and 13,648 control from 52 countries (INTERHEART study): case control study. The Lancet 2004;364:953-63. [PubMed] [Google Scholar].

9. Disania L.N., Pathak K. A, Punia K. R Autopsy study of brought dead cases in Jaipur, Rajasthan; Int J Cur Res Rev. 2014;6(22):6-9.

10. Gupta B.D, VaghelaP.C., Singh G, Mehta R, Futility of postmortem examinationin 'brought in dead' cases: A Retrospective Study; JPAFMAT, 2006; 6. ISSN 0972-5687.

11. Biswas A, Chattopadhyay S, Mazumder A, Adhya S, Autopsy study of Brought Dead cases at Malda, West Bengal; (IOSR-JDMS) e-ISSN: 2279-0853, p-ISSN: 2279-0861.Volume 16, Issue 10 Ver. IV (Oct. 2017), PP 37-39 